\title{
Multiple stakeholders's co-creation process in new product development: an exploratory analysis
}

\author{
Lidia Alexa ${ }^{1 *}$, Silvia Avasilcăi ${ }^{2}$, Adriana Bujor $^{3}$ \\ 1"Gheorghe Asachi" Technical University, Iasi, lidia.alexa@tuiasi.ro, Romania \\ 2"Gheorghe Asachi" Technical University, Iasi, silvia.avasilcai@tuiasi.ro, Romania \\ 3"'Gheorghe Asachi” Technical University, Iasi, adbujor@gmail.com, Romania
}

\begin{abstract}
In the this highly competitive market, a company's capacity to generate and market creative and original ideas is a key for success. But most companies have limited resources and so, knowledge creation can not be generated solely from within the firm. In order to expand their knowledge base, organizations begun to implicate stakeholders in all phases of the new product development process, from idea generation, selection, development and eventually, even to marketing the new products or services. In this context, the Internet and the new technologies represent a valuable instrument for companies, due to the fact that they can enhance the firms' ability to actively engage all their stakeholders in collaborative innovation. Our paper presents and evaluates the development and implementation of an online co-creation platform - E-PICUS addressed to multiple stakeholders of a new electronic product - Video Intercom providing insights into the specific capabilities a firm needs in order to manage co-creation and into partial results obtained through costumers' involvement in the innovation process.
\end{abstract}

\section{Introduction}

The fact of the matter is that the only constant truth these days is that everything is in a constant and rapid change, starting with technology and ending with the costumers needs and expectations. So, if a company wants to survive and succeed it needs to change and adjust as well just to keep the pace. In many industries, the ability to develop new products quickly, effectively, and efficiently has become the single most important factor driving a firm's success as presented by M. Schilling [1] and in order to do that, companies need to constantly create knowledge and innovate. But at the same time, most companies have limited resources and so knowledge creation can not be generated only from within the firm. In order to expand their knowledge base, organizations begun to implicate stakeholders in all the phases of the new product development process, from idea generation, selection, development and eventually, even to marketing the new products or services. In terms of the type of actors involved in the co-creation process, most often companies relay on primary stakeholders, such as customer, analyzed by N. E. Coviello and R. M. Joseph [2], competitors, discussed by W. Amaldoss and
A. Rapaport [3] or suppliers, examined by M. Song and J. Thieme [4], but research and practice have shown an important shift towards collaborating with multiple stakeholders simultaneously during the innovation process. Previous research shows that the involving different types of stakeholders throughout the innovation process represents an important factor for successful product and service development, as it aids in obtaining more detailed information about a firm's external environment, as emphasized by P. H. Driessen and B. Hillebrand [5].

For example, G. Cuccureddu [6] discuses DHL case which has implemented a multiple stakeholders' cocreation process by "working together with academics, politicians, public authorities and citizens in order to cocreate new offerings which address the challenge of decreasing urban traffic and a need for a greener economy".

\section{The E-picus experiment}

\subsection{Project Development}

The E-PICUS co-creation platform is being developed through the project „E-solutions for innovation through customer pro-active involvement in value creation to

Corresponding author: lidia.alexa@tuiasi.ro 
increase organizational competitiveness (E-PICUS)" and the project main scope is to develop an experimental model for e-solutions of innovation through customer pro-active involvement in product innovation, in order to improve organizational competitiveness on the international market. The platform was designed and tested using a video-intercom product developed by a highly innovative Romanian technology company located in Iasi, Electra. In this specific phase, the goal was to design a user friendly platform focused mainly on enhancing the back-stages of the new product development process (product design and testing) involving three types of stakeholders, namely, partners and distributors which are selling and installing the devices produced by the company, costumers (current users of intercoms or video intercom systems and potential users), and students from technical universities.

The platform development process had two separate stages: the first one consisted in an extensive literature review in order to determine the state-of-the-art and to gain a better understanding of the co-creation area, the existing open innovation and co-creation platforms and instruments, followed by a benchmarking analysis, which included an extensive number of online cocreation platforms and instruments developed, among others by Dell, analyzed by L. Alexa, M. Alexa and S. Avasilcăi [7], Heineken, presented in detail by $\mathrm{S}$. Avasilcăi and G. Rusu [8], BMW, studied by S. Avasilcăi and E. Gălățeanu (Avram) [9], Lego, reviewed by D. Zwick, S.J. Bonsu and A. Darmody [10], Barilla, examined by A. Bujor and S. Avasilcăi [11], IBM assessed by V. Blazevic and A. Lievens, [12], etc.

The goal of the benchmarking analysis was to identify the most frequent common elements included in all platforms, the best practices and the overall process of involving and engaging the stakeholders in the cocreation process in order to generate consistent and useful feedback. The analysis took into account the fact that the platform was designed for a multiple stakeholders' approach, involving costumers (current users of video intercom systems and potential users), partners and distributors which were selling and installing the devices produced by the company and students, mainly from technical universities.

The second stage of the development process focused mainly on the internal analysis of the company and materialized in several focus-groups with members of the research \& development, marketing \& sales and engineering departments. The qualitative research results assisted the implementation team in the process of identifying useful features for the online co-creation instrument, designing the main structure of the platform and deciding on the focal topics to be included in the cocreation community section, such as various aspects regarding the aesthetics and the functionality of the product. Another element discussed during the focusgroups focused on the challenges imposed by a multiple stakeholders' approach, because, as V.M. Waligo, J.
Clarke and R. Hawkins [13] emphasize, bringing a diverse group of stakeholders together leads to potential divergent goals and interests, communication difficulties, distrust among stakeholders, or conflict over value appropriation. Taking into account this element, the multiple stakeholders issue, in P. H. Driessen and B. Hillebrand opinion [5], the company needs to have a complex bundle of knowledge, skills and mechanisms in place to enable it to incorporate the voice of the stakeholders in its decision making processes, because in practice, stakeholders interests can often be conflicting due to divergent needs and expectations.

\subsection{Project Implementation}

The co-creation platform structure is simple and intuitive, with five sections in the main menu: Home, About us (a description of the project consortium), How it works (users manual), Our proposals (a description of the product in question - the Video Intercom and a list of functionality and design elements proposed to be enclosed in the final product, to be voted and evaluated/modified/improved by users) and Propose your idea (the online community feature that offers users the possibility to propose their own ideas for debate and to vote and comment on the ideas posted by other users).

In order to motivate the target group to access the platform and engage in the co-creation process they are to receive tangible benefits: the costumers have the opportunity to win (free of charge) a video intercom system, the partners received discounts and the students could earn an internship in the research and development department of the company.

In the end, the co-creation platform has two separate components: the first component provides users access into the community where they have the options to vote and comment the proposed functionalities and to suggest new ideas for product development and improvements. The second component focuses on a quantitative research and has a questionnaire designed for each of the three stakeholders' groups regarding the product features and options, asking for specific feedback from each target group, but with a set of common questions.

\subsection{Project Intermediary Results}

The co-creation platform has been online for users starting with October 2016. After six months, the platform has registered 993 sessions with an average duration of 5:44 minutes and 5,482 page views. At this point, the platform has 225 registered users and 221 subscribers.

There are also 33 new proposals and 49 comments coming from registered users, mostly referring to security functions, from adding new sensors to establishing connections to smartphones or to security interventions firms. Apart from commenting the

\footnotetext{
Corresponding author: lidia.alexa@tuiasi.ro
} 
proposals posted in the community, registered users can vote them with ratings from 1 to 5 and at this point there are 51 votes; the popularity of each proposal being another element taken into account when evaluating whether a feature/proposal should be integrated in the end-product. Most of the proposals regarding technical aspects are received from the partners and distributors stakeholder group, as they are the ones who have a direct contact with the end-users and they have to respond to potential malfunctions and/or customization requests. They have also added proposals and suggestions regarding after-sale services.

The other two stakeholder groups, customers and students, made suggestions concerning mainly aspects referring to aesthetics and customization/personalization of the video intercom.

The proposals receive feedback both from the other users on the platform and from members of the research development team of the company specifically assigned to interact and communicate with the users that bring ideas and suggestions for improvements.

Each idea will be further evaluated by the research development team in order to decide if the proposed feature or modification will be implemented in the final product.

In order to evaluate and decide on the features of the final product the company is developing a multiple criteria analysis of each proposal: an economic evaluation in terms of investment needed and increased cost of the end-product, an utility evaluation, in terms of specific needs for a higher number of consumers, a differentiation analysis: if the proposed feature ensures a significant differentiation from other products developed by competitors, an evaluation of the added value perception, if the proposal/feature is perceived as valuable by customers.

The platform will be online for this specific project until the end of June 2017, when all the feedback, the users' proposals and comments will be analyzed, evaluated and integrated (if the case) in the final product.

In terms of the quantitative research, at this point there are 25 questionnaires completed by partners/ distributors, 49 completed by customers, out of which $70,2 \%$ have an intercom, $29,8 \%$ don't own one and only $4,3 \%$ own a video intercom and 124 completed by students from technical universities.

In an effort to evaluate if there are any divergent perspectives between the three types of stakeholders, we conducted a brief comparative analysis of the answers provided at the common questions regarding the functionality features of the video intercom.

The leading part of the questionnaire focused mainly of functionality features and so the first question referred to users' interest toward additional warning options, with four alternatives provided by the company: fire sensor, flood sensor, window breaking in sensor and panic button. The answers used a 5 points rating scale, ranging from uninterested (1) to very interested (5) and our analysis focused on the 4 and 5 range. At the same time, users had the possibility to add new warning options after evaluating the four alternatives initially provided. For the first option, the fire sensor, $75 \%$ of partners/distributors, $89 \%$ of clients and $74 \%$ of students declared that they are interested and very interested. For the flooding sensor, 55\% of partners/distributors, $57 \%$ of clients and $57 \%$ of students declared that they are interested and very interested. For the window breaking in sensor, $55 \%$ of partners/distributors, $78 \%$ of clients and $66 \%$ of students declared that they are interested and very interested. For the panic button, $60 \%$ of partners/distributors, $57 \%$ of clients and $67 \%$ of students the declared that they are interested and very interested. There are no significant differences between the three type of stakeholders regarding the additional warning options. However, the choice to integrate the additional sensors will be made by the company after the project completion and after taking into account all the answers to the questionnaires and all the votes registered on the platform for each alternative.

The next question referred to sensor-terminal connection with two options: cable and Wi-Fi on a 5 points rating scale ranging from strongly disagree (1) and strongly agree (5). Again, the analysis focused on the 4 and 5 range. For the cable connection option, 50\% of partners/distributors, $28 \%$ of clients and $44 \%$ of students declared that they agree and strongly agree with this possibility. The Wi-Fi option was preferred by $65 \%$ of partners/distributors, $85 \%$ of clients and $81 \%$ of students. For this question as well there are no significant differences between the three type of stakeholders, most stakeholders leaning toward the WiFi option.

The next question referred to warning communication options for various events with five options: acoustic alarm, light alarm, message on the outdoor display, SMS/mobile alert, message to a security company. The answers used a 5 points rating scale, ranging from uninterested (1) to very interested (5) and the analysis focused on the 4 and 5 range. $65 \%$ of partners/distributors, $78 \%$ of clients and $63 \%$ of students declared that they are interested and very interested about the acoustic alarm. 50\% of partners/distributors, $59 \%$ of clients and $44 \%$ of students opted for the light alarm, while the message on the outdoor display was rated as interesting and very interesting by $40 \%$ of partners/distributors, $44 \%$ of clients and $48 \%$ of students. The highest values were registered for SMS/mobile alert: $80 \%$ of partners/distributors, $94 \%$ of clients and $76 \%$ of students, while the message to a security company was rated as interesting and very interesting by $70 \%$ of partners/distributors, $73 \%$ of clients and $82 \%$ of students. The answers regarding the warning communication options for various events were relatively similar between the three stakeholders, with no significant differences.

The next question discussed customization

\footnotetext{
*Corresponding author: lidia.alexa@tuiasi.ro
} 
alternatives with seven options: keys sound, keys sound volume control, keys sound length control, ringtone selection, ringtone volume control, ringtone length control, acoustic alarm volume control, each one rated on a 5 points rating scale, ranging from uninterested (1) to very interested (5).

The aspect regarding keys sound was rated as interesting and very interesting by $20 \%$ of partners/distributors, $29 \%$ of clients and $23 \%$ of students. The keys sound volume control was rated as interesting and very interesting by $40 \%$ of partners/distributors $38 \%$ of clients and $30 \%$ of students.

The keys sound length control was rated with 4 and 5 points by $5 \%$ of partners/distributors, $25 \%$ of clients and $28 \%$ of students. The ringtone selection was rated with 4 and 5 points by $50 \%$ of partners/distributors, $68 \%$ of clients and $43 \%$ of students. The ringtone volume control was rated with 4 and 5 points by $70 \%$ of partners/distributors, $68 \%$ of clients and $46 \%$ of students.

The ringtone length control was rated with 4 and 5 points by $70 \%$ of partners/distributors, $68 \%$ of clients and $43 \%$ of students. The acoustic alarm volume control was rated with 4 and 5 points by $60 \%$ of partners/distributors, $74 \%$ of clients and $58 \%$ of students.

The question regarding customization alternatives registered a wider range of values, with differences such as $25 \%$ (ringtone selection - costumers vs. students) to $27 \%$ (ringtone length - partners vs. students), the differences can be explained both by the fact that the question treats specific technical aspects and that it refers to customization and personalization. However, in order to evaluate the relevance for the end product, we need more data from a wider sample.

\section{Conclusion}

As useful and valuable co-creation can be for a company's performance, addressing the interests of a wide set of stakeholders can be a daunting task in terms of knowledge management and information integration in the new product development process due to possible divergences between the different stakeholders' needs and expectations.

In terms of managing the information, the company has appointed personnel from the research and development departments to actively engage in the platform and to interact with users regarding their ideas and proposal and at the end of the project an interdisciplinary team will further evaluate the proposals using a multiple criteria analysis to decide which functionality and design aspects will be integrated in the final product.

In terms of the quantitative analysis, our research so far has not detected significantly conflicting perspective from the three stakeholders involved in the co-creation process, but the results can register changes once the sample becomes larger.

This research was undertaken within the framework of the National Research Program PN II, financed by MEN UEFISCDI, project PN-II-PT-PCCA-2013-4-1811.

\section{References}

[1] M. Schilling, Strategic Management of Technological Innovation, 4th ed., 2013, McGraw Hill Education.

[2] N.E. Coviello, R.M. Joseph, "Creating major innovations with customers: Insights from small and young technology firms". Journal of Marketing, 76(6), 2012, 87-104.

[3] W. Amaldoss, A. Rapoport, "Collaborative product and market development: Theoretical implications and experimental evidence", Marketing Science, 24(3), 2005, 396-414.

[4] M. Song, J. Thieme, "The role of suppliers in market intelligence gathering for radical and incremental innovation", Journal of Product Innovation Management, 26(1), 2009, 43-57.

[5] P. H. Driessen, B. Hillebrand, "Integrating Multiple Stakeholder Issues in New Product Development: An Exploration", Journal of Product Innovation Management, 30 (2), 2013, 364-379.

[6] G. Cuccureddu, "DHL's open innovation contest and the quest for radical decentralization", accessed April, 12, 2017, from:http://www.innovationmanagement.se/2011/10/07/dhlopen-innovation-contest-and-the-quest-for-radicaldecentralization/, 2011.

[7] L. Alexa, M. Alexa, S. Avasilcăi, "An Empirical Research On Open Innovation and Co-Creation: The Ideastorm Project By Dell", Review of Management and Economic Engineering, Volume 13, No. 4 (54), 2014, 779-788.

[8] S. Avasilcăi, G. Rusu, "Co-Creation Value Through Customers' Proactive engagement: A Case Study on Heineken", Annals of The University of Oradea, Fascicle of Management and Technological Engineering, Issue 2, 2015, 100-105.

[9] S. Avasilcăi, E. Gălățeanu (Avram), "Innovation through developing consumers communities. Part II: Digitalizing the innovation processes", IOP Conf. Series: Materials Science and Engineering, 95, 2015.

[10] D. Zwick, S.J. Bonsu, A. Darmody, "Putting consumers to work: 'Co-creation' and new marketing govern-mentality", Journal of Consumer Culture, 8 (2), 2008, pp. 163-196.

[11] A. Bujor, S. Avasilcăi, "Co-creation innovation in consumer goods industry: The case of Barilla Group (B)", Annals of the Oradea University. Fascicle of Management and Technological Engineering, XXIV (XIV), 2015, 1-6.

[12] V. Blazevic, A. Lievens, "Managing innovation through customer cocreated knowledge in electronic services: an exploratory study", Journal of the Academy of Marketing Science, 6 (1), 2008, 138-151.

[13] V.M. Waligo, J. Clarke, R. Hawkins, "The 'leadershipstakeholder involvement capacity' nexus in stakeholder management", Journal of Business Research, 67(7), 2014, 13421352. 